\title{
Babelia: más allá del mall Análisis de la novela de Guillermo Fernández
}

\author{
Ángela Ramírez G.*
}

\section{RESUMEN}

Este texto pretende demostrar que Babelia presenta al menos tres distopías, y una utopía perversa donde la realidad transcurre en términos opuestos a los de una sociedad ideal. Para ello surgen las interrogantes: ¿Es esta una novela posmoderna? ¿Cuáles son los miedos presentes en el universo novelado? ¿Por qué se compara el mall con un Babel Bíblico?

Palabras clave: Posmodernidad, sociedad de consumo, distopías, novela, literatura.

\section{ABSTRACT}

The text shows up that Babelia represents at least three dystopias and one perverse utopia where the reality goes against the ideal society. Some questions arise from this point: Is this a postmodern novel? Which are the fears presented in the universe of the novel? Why is the mall compared with a Bible confusion?

Keywords: Posmodernity, society of greed, dystopias, novel, literature.

\section{Motivación}

El mall es signo posmoderno de nuestra cultura; se habla, incluso, de que son las catedrales góticas del siglo XXI, la extraterritorialidad del consumo, los diferentes usos que hacen las personas de estos sitios incrustados en el espacio urbano como un referente para ser analizados, desde varias perspectivas: sociológica, antropológica y desde la literatura. Esto es precisamente

Profesora de Comunicación y Lenguaje, Estudios Generales, UCR. Productora del programa "Onda UNED", UNED. Cursa la Maestría en Artes con énfasis en Cinematografía, UCR. 
lo que conlleva a analizar una novela como Babelia, pues en este texto, el centro comercial, el consumismo y la literatura light son signos presentes en una época globalizante.

Para Fernández, el mall en un pre texto, una sociedad como una gran torre de Babel, donde todos hablan diferentes lenguas y nadie logra comprenderse, paradoja actual en la sociedad de la información y del consumo que nos ofrece llegar al cielo.

La novela Babelia, tiene un universo temático muy contemporáneo, lo que permite analizar temas como el centro comercial, así como algunos de los temores presentes en esta era globalizante: violencia, consumismo, pérdida de esperanza en un futuro.

\section{Antecedentes}

Por ser una novela reciente, se publicó en el año 2006, Babelia no ha sido analizada en círculos académicos. Las únicas reseñas que se hacen es a través de internet, donde de forma informal se realiza una crítica sin método, tan solo impresiones que tiene el lector sobre el texto. Sin embargo, de las dos críticas sobre la novela podemos clasificar dos tópicos a los que hacen alusión, esto es, respecto a la importancia de la temática y a lo inverosímil de algunos personajes.

Para Diego Mora, "esta es una novela necesaria. Más que eso: urgente. La temática asociada a la globalización en Costa Rica y sus fenómenos sociales derivados eran una realidad que estaba esperando por un escritor arriesgado" (Mora, 2008: 1).Sin embargo para Mora, la construcción de los personajes "se perciben inverosímiles en muchos de sus diálogos, e incluso en algunas de sus acciones, cual le resta credibilidad a la historia, la falsea y le quita dramatismo" (Mora, 2008:1). Considera este crítico que el ritmo de la novela es lento y con una historia lineal.

En una bitácora electrónica (blog) aparece una alusión a la novela y la considera una narrativa floripondiosa, con metáforas infelices (infelicísimas), personajes inocuos, otros a los que en definitiva les falta mayor relieve y coherencia. Sin embargo, por ser anónimo tan solo lo mencionamos.

\section{Problemas de investigación}

- ¿Cuáles son los miedos presentes dentro del universo literario en la novela Babelia?

- ¿Por qué compara el Mall con un Babel bíblico?

- ¿Es Babelia una novela posmoderna?

Podemos adelantar desde ahora que Babelia es una novela posmoderna que trata de resaltar la distopía $\mathrm{y}$ advierte del temor hacia el consumo y el desencanto en el futuro. 


\section{Acercamiento teórico}

Para el análisis de la novela Babelia, es necesario establecer algunos conceptos importantes, tales como literatura posmoderna, centro comercial o mall, extraterritorialidad en el consumo.

Para Lyon, D. (1996), lo posmoderno se asocia con una sociedad de consumo de masas, formas de vida consumista que domina la existencia de sus miembros, donde la moda y los gustos son eclécticos. Señala que una de características de esta época es el estímulo al consumo, principalmente de bienes suntuarios en donde se da una producción de necesidades y deseos y "se presuponen los ingresos necesarios para mantener modos de vida consumistas, lo mismo que el ocio suficiente para permitírselos." (Lyon. 1996:103). La era posmoderna, se caracteriza por ser metropolitana, es decir, se desarrolla en contextos urbanos. Es así como surge el centro comercial o mall, en inglés, que se convierte en ese gran espacio donde se va a comprar, ya no para cubrir las necesidades básicas, sino como una actividad de ocio; en donde se va a pasear, y se convierte así en un parque temático. Porque como nos aclara Beatriz Sarlo, "el shopping-center, no importa cuál sea su tipología arquitectónica, es un simulacro de ciudad de servicios en miniatura, donde todos los extremos de lo urbano han sido liquidados." (Sarlo,1998:1). Para esta autora, el centro comercial es una nave espacial acondicionada por la estética del mercado: "Como una nave espacial, es posible realizar todas las actividades reproductivas de la vida: se come, se bebe, se descansa, se consumen símbolos y mercancías(...) (Sarlo. 1998:2).

Las ciudades posmodernas se han convertido en espacios inseguros, sitios que se atraviesan para ir de un lugar a otro, de calles oscuras y malolientes, ocupadas por grupos de población que son marginadas, excluidas de la sociedad de consumo. El centro comercial viene a reemplazar a la ciudad y es además un "artefacto perfectamente adecuado a la hipótesis del nomadismo contemporáneo: cualquiera que haya usado alguna vez un shopping puede usar otro, en una ciudad diferente y extraña de la que ni siquiera conozca la lengua o las costumbres." (Sarlo. 1998:3). Entrar a un mall se convierte en un lugar común, un espacio donde da la sensación de estar en casa, limpio, seguro, confortable.

Hay que hacer la distinción entre posmodernidad, que se refiere al agotamiento de la modernidad y se enfatiza en lo social, y posmodernismo, que acentúa el aspecto cultural. Se cuestiona los principios esenciales de la Ilustración. Otra característica es que se quiebra con las jerarquías del conocimiento, el gusto y la opinión. Otro fenómeno es la sustitución del libro impreso por la pantalla de televisión, el paso de la palabra a la imagen, del discurso a la figura, (Lyon. 1996: 22). 
En el ámbito de la literatura posmoderna, nos aclara Lyon, es difícil distinguir "las "novelas contemporáneas" y ciencia ficción (Lyon. 1996:105). Esto, porque se hace un abandono de las técnicas que ayudaban a comprender o incluso vencer la complejidad; los escritores "nos trasmiten su propia confusión sobre quiénes son y cómo responden a extraños y escindidos de superficies significantes (...). Por tanto, en lugar de advertirnos sobre un futuro temible nos presentan descripciones genealógicas del pasado reciente y el presente" (Lyon. 1996:106). Otra característica de la novela posmoderna es presentar el temor de la época, se presenta una visión paranoica, pero ya no del futuro, pues este no existe dentro de los cánones posmodernos, sino las distopías como el presente. Una utopía perversa donde la realidad transcurre en términos opuestos a los de una sociedad ideal, es decir, en una sociedad opresiva, totalitaria o indeseable. Los espacios en donde se desarrollan las temáticas son los espacios urbanos, la ciudad, que se convierten en centros de consumo en donde proliferan los centros comerciales y son los espacios que convocan a los habitantes. El parque, el museo, dejan de ser sitios de reunión. Y quedan para la otredad que se autoexcluye de participar en estos nuevos sitios posmodernos.

\section{Desarrollo}

\section{Sinopsis}

La novela nos narra la vida de Ivano, un joven de 19 años. Su trabajo consiste en teatralizar que es un comprador en el Mall para estimular el consumo. Su pareja en este performance es Gioconda, una joven guanacasteca, asidua lectora de libros de autoayuda y Víctor, joven frívolo, que sueña con ser un maripepino profesional. Ivano estudia en una universidad privada. Vive con su madre y hermana en Guadalupe, Goicoechea. Es una persona desencantada de la vida, que sueña con vivir en una torre de Babel para aislarse del mundo. Muere producto de una bomba de un grupo terrorista denominado Gea, que está en contra del consumismo.

\section{Personajes}

Ivano: joven guapo, estudiante de arquitectura, trabaja como modelo, ya que teatraliza que es un consumidor en el Mall. Odia su trabajo. Está enamorado de su compañera de trabajo, Gioconda, lectora voraz de libros de autoayuda.

Víctor: compañero de trabajo, modelo, trabaja como maripepino (bailarín erótico) en su tiempo libre. Sueña con irse a Canadá. 
Andrea: hermana de Ivano, está enamorada virtualmente de un actor de televisión. Se embaraza de Víctor.

Madre de Ivano: auxiliar de enfermería, alienada por la religión, el marido la abandona. Mujer castrada en la parte sexual, decide vivir por y para sus hijos.

Julio: poeta, sin tiempo ni territorio. Anda en búsqueda de la poesía que haga vibrar a esta generación. Estuvo internado en el psiquiátrico, vive de una miserable pensión que le deja su madre

Casimiro: fantasma que habita en el Mall, se suicidó en este lugar por no poder comprarle un regalo a su esposa el día de los enamorados. Se le aparece a Ivano. Poco a poco comienza a desvanecerse en los muros del lugar que lo estimuló a cometer el suicidio.

Babel: drogadicto, sociólogo, dibuja a los muertos, se enamoró de una prostituta, le hace el amor cuando está muerta. Gusta de estar en el cementerio de Guadalupe. Se convierte en el mejor amigo de Ivano. Hombre sin utopías, tan solo desea drogarse para olvidar la realidad que lo circunda.

Rima: mujer millonaria, está enamorada de Raimundo, un hombre que asesinó a tres hombres por haber contaminado el río del pueblo. Crea un grupo terrorista ecológico denominado Gea. Está casada con Federico, un abogado millonario, cínico y mujeriego. Recluta a Víctor en su organización.

Usher y la Momia: dos ex revolucionarios que profanan tumbas de burgueses como forma de manifestarse contra el sistema.

\section{Espacios en donde se} desarrolla la novela

\section{El Mall}

Es una Torre de Babel contemporánea: un lugar de desencuentros, confusión, caos. El consumo convoca, sin embargo, no todos pueden hacerlo, es por ello que hay varias categorías de asistentes a este lugar: consumidores, mirones, y gentes miserables o parásitos, pues no tienen el poder adquisitivo para realizar compras, incluso, un hombre se suicida porque no se encuentra en posibilidad de comprar un regalo a su mujer el día de San Valentín, o utilizar ese dinero para hacer frente a los gastos de consumo más inmediato como es la comida y el pago de la mensualidad de la casa.

Se ubica en San José, "se erguía en la esquina diagonal a una rotonda, enorme construcción de forma rectangular color ocre, con largas filas de ventanales laterales" (Fernández. 2006: 1).

Se convierte en el Mall, en donde los que consumen son los socios natos y no hay cabida para los mirones; así "el paseante es nuestro enemigo, hasta que no compre y ocupa un espacio carísimo en nuestra corporación robando el oxígeno que necesitan” (...) (Fernández. 2006: 
36). La gente miserable (inmigrantes, desempleados, pobres) que deambulan por los pasillos del centro comercial, son considerados como personas que no existen, "como un enjambre de moscas en un basurero donde ni siquiera extraen la jalea podrida que se exhala en la punta de un pan añejo.” (Fernández. 2006:36).

\section{El Cementerio}

Cada noche, después de realizar su trabajo como modelo para estimular el consumo en el Mall, se va caminando para su casa en Guadalupe, donde debe recorrer tres kilómetros. Un día se ve tentado a entrar por la parte trasera de la malla del cementerio de Nuestra Señora de Guadalupe. "Estando del otro lado, el camposanto se le reveló espléndido" (Fernández. 2006: 57). En este sitio, Ivano experimentó la quietud del sitio, una quietud casi perfecta.

Es además, en donde conoce a Babel, el dibujante, adicto al crack que se convierte en su amigo de Ivano.

El cementerio se convierte en el espacio en donde conoce la amistad, con Babel, "el hombre que le había estimulado el pensamiento, una facultad que en el Mall trabajaba en su rango mínimo" (Fernández. 2006: 60). Es también donde Ivano descansa.

La muerte es vista "como un pasado un lugar más noble que el tiempo presente" (Fernández. 2006: 65).
Otro cementerio dentro del relato es el General, en el Barrio Corazón de Jesús, "que es de los ricos del país" (Fernández. 2006: 222). Este se convierte en espacio para que Usher y Momia, dos desencantados, realicen su "propia revolución (...) a falta de cambiar las estructuras del país, hemos decidido despojar a los muertos que fueron los dueños, que usurparon, maltrataron (....) privaremos a estos oligarcas malnacidos del debido descanso" (Fernández, 2006: 225).

Es un espacio de división de clases, de odios, rencores, el lugar donde se enterró la utopía revolucionaria.

\section{Torre de Babel}

Yavé bajó a ver la ciudad y la torre que los hombres estaban levantando, y dijo Yavé: "Veo que todos forman un solo pueblo y tienen una misma lengua. Si esto va para adelante, nada les impedirá desde ahora que consigan todo lo que se propongan. Pues bien, bajemos y confundamos ahí mismo su lengua, de modo que no se entiendan los unos a los otros".

Así Yavé los dispersó sobre la superficie de la tierra, y dejaron de construir la ciudad. Por eso se llamó Babel, porque allí Yavé confundió el lenguaje de todos los habitantes de la tierra, y desde allí los dispersó Yavé por toda la tierra" (Génesis 11, 4-9).

La intención de los hombres de acuerdo con este pasaje era la unidad 
de la lengua y su pueblo; sin embargo, esto fue visto por Yavé como un signo de poder, de fuerza, de irreverencia ante el saber divino. Al crearles confusión con sus lenguas no pudieron comunicarse y la unidad que otrora soñaron, se fragmentó, por lo que tuvieron que dispersarse por el mundo.

Babel toma este seudónimo "no hay nombre que exprese más lo que yo soy. Quiero subir a los cielos pero mi alma es un desorden de los once mil diablos" (Fernández. 2006: 60).

Para Ivano, la Torre de Babel tiene un significado diferente al caos. Para él simboliza refugio, "significa el sueño de alejarnos de la tierra y de acampar más cerca del vuelo de las aves o del vuelo mismo en abstracto" (Fernández. 2006: 89). Para el joven, "Dios se cabreó con los hombres porque convirtieron la Torre en un supermercado" (Fernández. 2006: 89). Mientras que para Julio, el poeta sin tiempo, la Torre de Babel es "lo que vivimos hoy. Es el intento de conexión con el poder absoluto, que es infierno inevitable. Son las bombas atómicas, las sectas religiosas, la manipulación genética" (Fernández. 2006: 89).

Para Ivano, el construir una torre significaba, no como en el pasaje bíblico, un espacio para unificar, sino un lugar para alejarse del mundo, "Una torre bien alta es lo que necesito, y desde allí mirar a los seres humanos como pulgas en los cuadrantes." (Fernández. 2006: 111).

La madre de Ivano, luego de ser abandonada por el esposo, verse con dos hijos, en total pobreza, se refugió en la religión como una salida a su desesperación de buscar respuestas. Ella era la causante de haber construido en su hijo, la historia de Babel como sinónimo de refugio, y fue su inspiración. En una conversación que tiene con su madre, Ivano descubre esta verdad: "Retrocedió a tientas hacia las nieblas de su cuarto, y le blasonó la mente el recuerdo confuso de la mujer construyendo su propia torre, para no percibir su desdicha amorosa y su rutina endemoniada en el hospital, y en él muy pequeño escuchando cada una de sus versiones extrañas. No pudo comprender si fue un descubrimiento patético o liberador”. (Fernández. 2006:177).

\section{Distopías}

La novela posmoderna se caracteriza de acuerdo con Lyon, D. (1996), por la presencia de distopías. En el texto Babelia de Guillermo Fernández, encontramos tres distopías: el grupo Gea, quienes hacen actos terroristas para reivindicar a la madre naturaleza; su líder espiritual, Raimundo, quien decapitó a tres hombres que habían contaminado el río de su pueblo. "Hijos de Gea habrían de nacer capaces de matar a otros solo para proteger a un colibrí, 
por mantener intacta la arboleda, por custodiar una ruta de montaña." (Fernández. 2006:16). Realizan actos vandálicos reivindicando a la Madre Naturaleza, Gea. En uno de los atentados, colocan una bomba en el cajero automático del banco y "procedieron a romper el dinero que veían en buen estado, desgarrando los billetes con sus manos y pateándolos con desprecio y avidez." (Fernández. 2006: 312). En este atentado, muere Ivano y Chavela, una indigente que custodiaba los cajeros automáticos. Sin embargo, esto no es visto por el líder de la banda como "daños colaterales -susurró-. En honor de nuestra madre Gea. ¡Muerte al dinero! (Fernández. 2006: 313). El líder era Víctor, quien reconoce dentro de las víctimas a Ivano, su compañero de trabajo, quien le había ofrecido posada en su casa, y ser el tío de su futuro hijo. Sin embargo, esto no lo detiene y considera tan solo que fue un inconveniente.

Otra utopía perversa, presente en el texto, es lo referente a la profanación de tumbas que realizan Usher y la Momia, supuestamente para reivindicar, al menos, la utopía de la lucha de clases; además, como un acto de amor de Usher hacia su ex novia burguesa Gloria, un cariño que no se pudo concretar por las diferencias sociales; sin embargo, a la mañana siguiente, cuando Ivano le lleva de regalo una caracola como sinónimo de amor y de sueños, Usher se ríe de él, y le comenta que los actos que presenció en el cementerio no tenían ningún carácter revolucionario ni de amor, tan solo de vandalismo y espectacularidad, un acto de borrachera: "La noche que me viste hablando de Gloria estaba bastante borracho. Para serte sincero, ya no me importa lo que la cabrona haga con su vida. Podría volverla de nuevo y nada se conmovería dentro de mí." (Fernández. 2006:251).

Ivano es el personaje principal de la novela, un joven de 19 años, desencantado de la vida, al que le fastidian los problemas familiares: su hermana alienada por la televisión, su madre absorta en la religión, su amor platónico, Gioconda, compañera de trabajo, perdida en las utopías de la literatura de autoayuda.

Para Ivano, la única solución para construir un mundo más habitable es construir una Torre de Babel, para aislarse del mundo, la misma que su madre había construido para aislarse de las vicisitudes que la vida le estaba proporcionando en una etapa de crisis familiar. Para él la Torre "había sido construida para convertirse en un bastión para los hombres y las mujeres que odiaban la cercanía del fango terrenal, la fábrica silenciosa de cada jornada de dolor y espanto en los abismos de la vida. Una torre significaba también la conexión con el universo, con las estrellas, con la grandeza del más allá" (Fernández. 2006:75). 
El único personaje que muestra cierto optimismo por la vida es Julio el poeta desfasado, que al menos tiene la esperanza de crear el poema que sea leído por la generación de Ivano, considera, además, que "las estrellas por más que digan los escépticos, no son simples bolas de fuego. Son algo más (...)" (Fernández. 2006: 302).

\section{Conclusiones}

El Mall es un pre-texto para presentar el caos de nuestra sociedad contemporánea: vandalismo, violencia, la deshumanización, alienación a la religión, la televisión, la literatura de autoayuda, el consumismo.

Los personajes de Babelia no creen en un futuro, ni tratan de construirlo; son seres desencantados, cínicos, que se autodestruyen de diferentes formas: ya sea por el crack, el alcoholismo, o por la violencia urbana.

Sus personajes hablan diferentes lenguas, y en cada uno de ellos hay un caos, que los convierte en habitantes de un babel terrenal, incomunicados, desarticulados por diferentes lenguajes: el de la sociedad mediática, el del consumo, de la desesperanza, de la poesía sin leer, de la palabra sin sentido de la literatura light.

La muerte de Ivano, el personaje principal, es causada por una bomba puesta por el grupo ecológico Gea en un acto reivindicativo contra el consumo; esto confirma que la desaparición física de este joven de diecinueve años era la única salida a una persona que lo único que aspiraba en la vida era encerrarse en una torre de marfil para aislarse del mundo, una sociedad que le asqueaba por banal, y de la cual paradójicamente, él era parte; incluso, era un modelo por seguir ya que representaba un papel como consumidor, por tener muy buena apariencia física, como dicta la sociedad posmoderna.

En la sociedad representada en el universo temático de Babelia, no hay un proyecto de vida, todo es caos, desencanto, degradación, se vive de la ilusión, de la re-presentación de lo mediático, un eterno performance en este escenario consumista, donde la felicidad en el consumo es solo un eufemismo.

\section{Bibliografía}

Fernández, G. (2006). Babelia. Costa Rica: Editorial Universidad de Costa Rica.

La Biblia Latinoamericana (1995). España. Editorial Verbo Divino.

Lyon, D. (1996). Posmodernidad. España: Alianza Editorial.

Mora, D. (2008). Anotaciones sobre Babelia de Guillermo Fernández. Obtenida el 02 de diciembre, en http://www.estaciontropical.blogspot.com/

Sarlo, B. (1998). El Centro Comercial. Obtenida el 30 de setiembre de 2008,

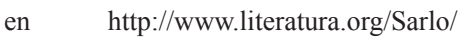
bscentro.html 
